\title{
Evaluation of an ELISA and immunoblotting for studying the humoral immune response in Anguillicola crassus infected European eel Anguilla anguilla
}

\author{
K. Knopf ${ }^{1, *}$, K. Naser ${ }^{2}$, M. H. T. van der Heijden ${ }^{3}$, H. Taraschewski ${ }^{1}$ \\ ${ }^{1}$ Zoologisches Institut — Ökologie, Universität Karlsruhe (TH), Kaiserstr. 12, 76128 Karlsruhe, Germany \\ ${ }^{2}$ Landesgesundheitsamt Baden-Württemberg, Wiederholdstr. 15, 70174 Stuttgart, Germany \\ ${ }^{3}$ Wageningen University, Department of Animal Sciences, Fish Culture and Fisheries Group, PO Box 338, \\ 6700 AH Wageningen, The Netherlands
}

\begin{abstract}
The applicability of an enzyme-linked immunosorbent assay (ELISA) for the detection of anguillicolosis in feral eels was examined using a crude antigen preparation from the body wall of adult Anguillicola crassus. The screening consisted of samples from 100 feral European eels Anguilla anguilla. As a reference the actual status of infection was determined by dissection of the eels' swimbladders. The ELISA results were compared with a background value calculated from the results obtained from 43 non-infected farm eels. The screened samples had a high prevalence of $A$. crassus $(83 \%)$; however, the specificity and the negative predictive value of the ELISA were low compared to the high positive predictive value. Nonetheless, the reproducibility (precision) of the test was satisfactory, and for the non-infected reference group specificity was $97.7 \%$. Although the ELISA, as used in the present study, is not applicable for diagnostic purposes, it represents a useful tool for the investigation of the specific humoral immune response of eels against $A$. crassus under controlled experimental conditions. Immunoblots using crude antigen preparations from different parts of adult A. crassus as well as a crude somatic third-stage $\left(\mathrm{L}_{3}\right)$ antigen preparation illustrated that only antigens associated with the body wall of adult $A$. crassus are potentially suitable for diagnostic purposes. Despite the fact that antibodies against Raphidascaris acus cross-reacted with 3 body wall antigens of $A$. crassus, the most encouraging results were obtained with the antigen preparation from the outer cuticle of adult A. crassus which yielded a conspicuous, broad band at about $100 \mathrm{kDa}$.
\end{abstract}

KEY WORDS: Anguilla anguilla $\cdot$ Anguillicola crassus $\cdot$ Raphidascaris acus $\cdot$ Antigens $\cdot$ Crossreactivity $\cdot$ Serodiagnosis $\cdot$ ELISA $\cdot$ Immunoblotting

Resale or republication not permitted without written consent of the publisher

\section{INTRODUCTION}

The dracunculoid nematode Anguillicola crassus is an original parasite of the Japanese eel Anguilla japonica. The adult worms live in the swimbladder

*Present address: Institute of Freshwater Ecology and Inland Fisheries, Department of Inland Fisheries, Müggelseedamm 310, PO Box 850119, 12561 Berlin, Germany.

E-mail: klaus.knopf@igb-berlin.de lumen and feed on their host's blood (Kuwahara et al. 1974, Moravec \& Taraschewski 1988). After A. crassus was introduced to Europe, the parasite spread rapidly over the indigenous stocks of the European eel Anguilla anguilla (Moravec 1992). In contrast to the original host $A$. japonica, the new host $A$. anguilla appears to be much more susceptible to $A$. crassus infection, which is indicated by a higher prevalence and abundance of the nematode (Egusa 1979). The parasites cause severe histopathological alterations of the swim- 
bladder wall in European eels (Van Banning \& Haenen 1990, Molnár et al. 1993, Molnár 1994, Haenen et al. 1996, Würtz \& Taraschewski 2000), resulting in a malfunction of the organ (Würtz et al. 1996).

So far, enzyme-linked immunosorbent assay (ELISA) and immunoblotting have been applied either to demonstrate the humoral immune response of the European eel against Anguillicola crassus or to diagnose anguillicolosis in feral eels. Höglund \& Pilström $(1994,1995)$ developed an A. crassus-specific ELISA using polyclonal rabbit anti-eel immunoglobulin antibodies. Since the whole-worm extract used as crude antigen yielded high background values, they purified the adult nematode antigen either by biochemical methods (Höglund \& Pilström 1994) or simply by dissection of adult $A$. crassus (Höglund \& Pilström 1995). Supported by an immunoblot analysis, the authors described antigens associated with the adult nematode cuticle as being the most specific for the differentiation between positive and negative eel sera in the ELISA.

This method was applied with slight modifications by Haenen et al. (1996) for a screening of 38 wildcaught eels. Instead of polyclonal antibodies the authors used monoclonal antibodies reactive with the light chain of eel immunoglobulin. However, there appeared to be no significant correlation between the parasite burden of the swimbladder and the test results. Békési et al. (1997) carried out an ELISA with a cuticularoesophageal antigen preparation and polyvalent rabbit anti-eel antibodies. They examined 21 feral eels and also found no correlation between the antibody levels and the intensity of infection.

Using the immunoblot technique, it was shown that antibodies in sera of naturally infected European eels recognise several antigens of adult Anguillicola crassus (Buchmann et al. 1991, Höglund \& Pilström 1995, Haenen et al. 1996, Nielsen \& Buchmann 1997). Although the presence of certain clearly defined bands was repeatedly described, the results do not correspond completely. It is still questionable whether the reactions against some major antigens are specific and sensitive enough for diagnostic or epizootiological purposes.

In the present study, a screening collective of 100 feral European eels was used to examine the serological tests mentioned above with respect to their diagnostic value in terms of specificity, sensitivity and positive and negative predictive value (Abel 1993). The use of Raphidascaris acus, a nematode dwelling in the intestine of eels, offered a good opportunity to investigate the immunodiagnostic problem caused by the crossreactions of antibodies to parasite antigens (Voller \& De Savigny 1981). For the first time, immunoblots using a crude antigen from the gelatinous outer part of the cuticle of adult Anguillicola crassus and a somatic crude antigen of third-stage larvae $\left(\mathrm{L}_{3}\right)$ are presented.

\section{MATERIAL AND METHODS}

Source of antigens. Adult Anguillicola crassus and Raphidascaris acus were collected from naturally infected eels and washed in phosphate buffered saline, (PBS) $\mathrm{pH}$ 7.2. Total $R$. acus were used for the preparation of a whole-worm extract. A. crassus were divided into outer part of the cuticle (see Taraschewski et al. 1988), body wall, male and female reproductive system, intestinal wall, intestinal content, and anterior part including the oesophagus. The intestinal wall was rinsed with PBS to remove any intestinal content. $\mathrm{L}_{3}$ of A. crassus were produced following Haenen et al. (1994), modified as described recently (Knopf et al. 1998). The $L_{3}$ were used completely for the preparation of somatic larval antigen.

Serum samples. The screening collective consisted of 100 feral eels Anguilla anguilla taken as samples from the river Rhine nearby Karlsruhe, Germany, by electro fishing in August 1995. Negative control sera were taken from 43 non-infected eels purchased from a commercial fish farm (Limnotherm, Bergheim, Germany). A spot-check of 15 eels was performed to confirm that eels from this source were free of Anguillicola crassus as stated in previous studies (Würtz et al. 1996, Knopf et al. 1998, Sures et al. 1999a). Blood samples were drawn from the caudal vein without using an anaesthetic or anticoagulant. The blood was allowed to clot for $2 \mathrm{~h}$ at $20^{\circ} \mathrm{C}$ and centrifuged for $5 \mathrm{~min}$ at $2000 \times g$. Sera were collected and stored at $-70^{\circ} \mathrm{C}$.

Additionally, antisera against Anguillicola crassus or Raphidascaris acus were raised in uninfected farm eels weighing approximately $90 \mathrm{~g}$, which were kept individually at a water temperature of $20^{\circ} \mathrm{C}$. The eels received a single intraperitoneal injection with adult whole-worm homogenates (AWWH) of the respective nematodes. AWWH was produced by sonication of adult worms in PBS on ice $(5 \times 5 \mathrm{~s}, 50 \mathrm{~W})$. According to Höglund \& Pilström (1995) each eel received $0.2 \mathrm{ml}$ of a solution containing AWWH protein at a concentration of $1 \mathrm{mg} \mathrm{ml}^{-1}$ emulsified in an equal volume of Freund's complete adjuvant (Sigma, Deisenhofen, Germany). For control eels AWWH was substituted by PBS. Blood samples were taken prior to the immunisation and $25 \mathrm{~d}$ after injection. Sera were prepared and stored as described previously.

Detection of Anguillicola crassus and swimbladder lesions. Swimbladders of the eels were examined macroscopically and microscopically for adult and larval Anguillicola crassus. Swimbladder lesions were scored according to Hartmann (1994), ranging from damage class 0 , without tissue alterations, to damage class 4, with heavily thickened swimbladder walls. Additional to the Hartmann (1994) criteria pigmentation of the swimbladder wall was included in the definition of damage class 1. 
ELISA. The ELISA in this study was carried out with an antigen preparation from the body wall of Anguillicola crassus. A preliminary sodium dodecyl polyacrylamide gel electrophoresis (SDS-PAGE) analysis (Fig. 1) had revealed that the body wall antigen preparation from A. crassus used in this study was similar to the so-called cuticle preparation of Höglund \& Pilström (1995). This was shown to be the most suitable fraction of adult A. crassus for an ELISA (Höglund \& Pilström 1995). In order to examine the cross-reactive potential of the antibodies against $A$. crassus a somatic antigen preparation of Raphidascaris acus was used.

Both crude antigens were prepared by sonication on ice $(5 \times 10 \mathrm{~s}, 50 \mathrm{~W})$ in a 10 -fold amount of sarcosyl-TEbuffer (10 mM Tris, 1 mM EDTA, $2 \%$ N-Lauroylsarcosine-sodium salt, $\mathrm{pH}$ 8.0) and centrifuged for $20 \mathrm{~min}$ at $16000 \times g$. The supernatant was stored at $-70^{\circ} \mathrm{C}$ until use. The protein content of the antigen preparation was determined by the method of Lowry et al. (1951) using bovine serum albumin (BSA; Fluka, Buchs, Switzerland) as standard.

Polystyrene microtitre plates (Nunc, Kamstrup, Denmark) were coated overnight at $4{ }^{\circ} \mathrm{C}$ with the crude antigen extracts at a concentration of $1.5 \mu \mathrm{g} \mathrm{ml}^{-1}$ in carbonate coating buffer $\left(10 \mathrm{mM} \mathrm{Na} \mathrm{CO}_{3}, 35 \mathrm{mM}\right.$ $\mathrm{NaHCO}_{3}, \mathrm{pH}$ 9.6). The plates were washed $3 \times$ with PBS containing $0.05 \%$ (v/v) Tween 20 (PBS-T), blocked with $1 \%(\mathrm{w} / \mathrm{v})$ BSA in PBS-T (PBS-T-BSA) for $3 \mathrm{~h}$ at $20^{\circ} \mathrm{C}$ and washed $4 \times$ with deionised water. After drying for $30 \mathrm{~min}$ at $37^{\circ} \mathrm{C}$ in vacuum, the plates were covered with plastic tape and stored at $-70^{\circ} \mathrm{C}$ until use.

Eel sera were tested in duplicate at a dilution of 1:100 in PBS-T-BSA and incubated for $1 \mathrm{~h}$ at $37^{\circ} \mathrm{C}$. As secondary and tertiary antibodies, monoclonal mouse IgG specific for eel immunoglobulin heavy chain (WEI 1, Van der Heijden et al. 1995) diluted 1:500 in PBS-T-BSA and sheep anti-mouse IgG conjugated with horseradish peroxidase (AP271, The Binding Site, England) diluted 1:1000 in PBS-T-BSA were used, respectively. Both the secondary and tertiary antibody were incubated for $45 \mathrm{~min}$ at $37^{\circ} \mathrm{C}$. The wells were filled with $75 \mu \mathrm{l}$ each time and after the incubation steps the plates were washed $3 \times$ with PBS-T. Finally $75 \mu$ l substrate (o-phenylenediamine, Abbott, Wiesbaden, Germany) was added and the reaction was stopped after 15 min with $50 \mu l 2 \mathrm{~N} \mathrm{H}_{2} \mathrm{SO}_{4}$ per well. The absorbance was measured at $492 \mathrm{~nm}$ (Titertek Multiskan, Flow Laboratories, Meckenheim, Germany). Preliminary tests showed that secondary and tertiary antibodies do not bind non-specifically.

Valuation of the ELISA. To classify the measurements to be positive or negative, a cut-off value was calculated by adding the mean absorbance value and 3 times the standard deviation (mean $+3 \mathrm{SD}$ ) of the sera from non-infected control eels.

To estimate the diagnostic value of the test, the specificity, sensitivity and the predictive value were calculated for the screened samples according to Abel (1993). The equations are shown in Table 1. As external reference ('gold standard') the presence or absence of Anguillicola crassus and pathological alterations of the swimbladder wall were used. Three different definitions of 'real positive' were applied for the calculation of the test parameters: (1) actual infection (adults and/or larvae) together with swimbladder alterations, if present, suggesting that previous infections had
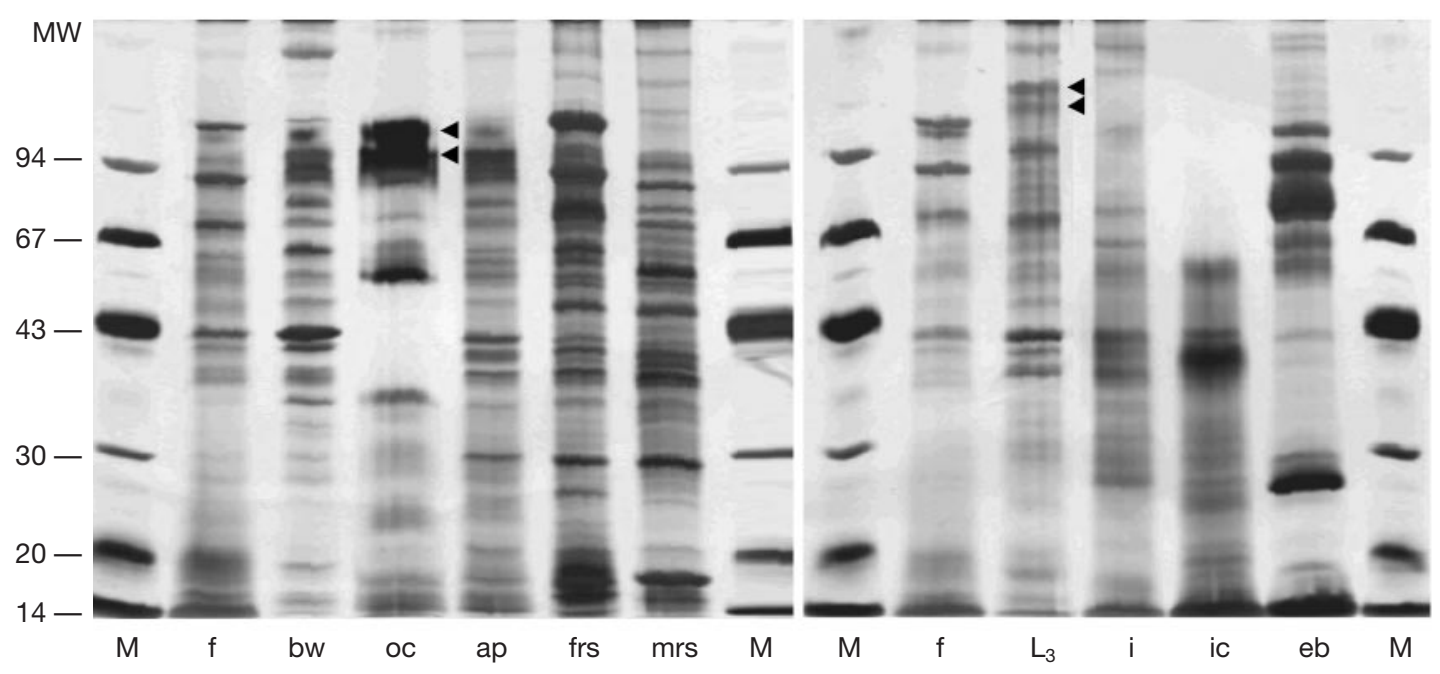

Fig. 1. SDS-PAGE analysis of different antigen preparations of Anguillicola crassus, silver stained. (M) Molecular weight markers, (f) somatic female, (bw) body wall of adults, (oc) outer cuticle of adults, (ap) anterior parts of adults, (frs) female reproductive system, (mrs) male reproductive system, $\left(\mathrm{L}_{3}\right)$ somatic $\mathrm{L}_{3}$, (i) intestine of adults, (ic) intestinal content of adults, (eb) eel blood. Molecular weights (MW) are indicated in kDa. Bands mentioned in the text are indicated by arrowheads 
Table 1. Calculation of sensitivity (Se), specificity (Sp), positive predictive value $\left(\mathrm{PV}_{\mathrm{p}}\right)$ and negative predictive value $\left(\mathrm{PV}_{\mathrm{n}}\right)$ according to Abel (1993)

\begin{tabular}{|lcc|}
\hline Test & \multicolumn{2}{c|}{ Screened samples } \\
& Real positive & Real negative \\
\hline Positive & $a$ & $b$ \\
Negative & $c$ & $d$ \\
& $\mathrm{Se}=\frac{a}{a+c}$ & $\mathrm{Sp}=\frac{d}{b+d}$ \\
& $\mathrm{PV}_{\mathrm{p}}=\frac{a}{a+b}$ & $\mathrm{PV}_{\mathrm{n}}=\frac{d}{c+d}$ \\
\hline
\end{tabular}

occurred; (2) actual infection including the presence of $\mathrm{L}_{3}$ and $\mathrm{L}_{4}$ (fourth-stage) larvae; or (3) actual infection with adult nematodes.

Additionally, the precision of the test is given as the $\mathrm{SD}$ in percent of the mean value from simultaneous (intra-assay coefficient of variation) and repeated (inter-assay coefficient of variation) measurements.

Immunoblot. SDS-PAGE was performed under reducing conditions in the Phast-System (Pharmacia LKB, Uppsala, Sweden) with purchasable homogenous gels containing $12.5 \%$ polyacrylamide (Pharmacia LKB). The different fractions of Anguillicola crassus, entire Raphidascaris acus and blood from an uninfected eel were dissolved in sample buffer, $\mathrm{pH}$ 6.8, containing $50 \mathrm{mM}$ Tris, $10 \%$ (v/v) glycerol, $7 \%$ (w/v) sodium dodecyl sulphate (SDS), 1 mM EDTA, $1 \mathrm{mM}$ phenylmethyl sulfonylfluoride (PMSF) and $3 \%(\mathrm{w} / \mathrm{v})$ dithiothreitol (DTT). A preliminary trial performed with additional protease inhibitors following Maizels et al. (1991) revealed the same results as using the sample buffer described above.

The samples were heated for $3.5 \mathrm{~min}$ at $95^{\circ} \mathrm{C}$ and centrifuged for $20 \mathrm{~min}$ at $16000 \times \mathrm{g}$. The supernatant was aliquoted and stored at $-70^{\circ} \mathrm{C}$ until use. The protein content of each antigen preparation was adjusted for an optimal separation and sensitivity. The gels were run with $220 \mathrm{~V}$ and $10 \mathrm{~mA}$ at $15^{\circ} \mathrm{C}$ for $70 \mathrm{VAh}$. If not used for Western blotting, gels were silver stained according to the manufacturers instructions.

Semidry Western blotting was carried out in a discontinuous buffer system (Holzhauer 1988) at $15^{\circ} \mathrm{C}$ for 20 min with $20 \mathrm{~V}$ and $25 \mathrm{~mA}$ on a polyvinyldiene fluoride (PVDF) membrane (Pall Gelman Sciences, Roßdorf, Germany) in the Phast-System (Pharmacia LKB). Afterwards the membrane was washed $3 \times 10 \mathrm{~min}$ in distilled water, cut into strips, dried in vacuum at $37^{\circ} \mathrm{C}$ and stored at $-70^{\circ} \mathrm{C}$.

The strips were incubated overnight at $4^{\circ} \mathrm{C}$ with eel sera diluted 1:100 in PBS-T, washed $3 \times 15$ min in PBS-T and were subsequently incubated for $1 \mathrm{~h}$ at $37^{\circ} \mathrm{C}$ with WEI 1 (Van der Heijden et al. 1995) diluted 1:500 in PBS-T and for $1 \mathrm{~h}$ with sheep anti-mouse IgG conjugated with horseradish peroxidase (AP271, The Binding Site, Birmingham, United Kingdom) diluted 1:1000 in PBS-T. Following each incubation step, the strips were washed $3 \times 15$ min with PBS-T. A freshly prepared solution of $30 \mathrm{mg}$ diaminobenzidine (DAB) dissolved in $500 \mu$ dimethylsulfoxide (DMSO) added to $100 \mathrm{ml}$ PBS with $40 \mu \mathrm{l} 30 \% \mathrm{H}_{2} \mathrm{O}_{2}$ was used for the substrate reaction which was stopped after $30 \mathrm{~min}$ with demineralised water.

The molecular weights of the denatured proteins were estimated by running calibration proteins (Pharmacia LKB). For inter- and extrapolation of molecular weight values Bio-Gene V.97 software (Vilber Lourmat, Marne-la-Vallée, France) was applied.

\section{RESULTS}

\section{Results by dissection}

The prevalence of Anguillicola crassus (adults and larvae) in the examined samples of 100 feral eels was $83 \%$. In 13 specimens only larvae were found. The abundance of A. crassus was $4.6 \pm 4.8$ (mean $\pm \mathrm{SD}$ ) and the intensity of infection was $5.5 \pm 4.7$ (mean \pm SD). $88 \%$ of the eels examined showed more or less severe alterations of the swimbladder wall.

\section{ELISA}

The quantity of specific antibodies to Anguillicola crassus in the peripheral blood neither correlated with the apparent worm burden, nor with the total number of $A$. crassus nor with the number of adult or larval nematodes. Likewise, a correlation between the ELISA results and the degree of swimbladder lesions was not found. Fig. 2 shows a survey of these findings with regard to the total numbers of A. crassus. Differentiation of adult and larval nematodes, respectively, yielded a similar picture (not shown). Some ELISA readings exceeded the linear range (>2.0) because the assay was initially optimised for a high sensitivity. Anyhow, they can be interpreted as highly positive.

The negative control sera from non-infected farm eels showed an optical density of $0.300 \pm 0.116$ (mean $\pm \mathrm{SD})$, which resulted in a cut-off value of 0.648 . Hence, 32 eels of the screened samples were seronegative and 68 were seropositive, respectively. Table 2 shows a survey of the ELISA findings compared to the condition of the eels determined by dissection for each of the 3 defined 'real positive' results as well as the calculated sensitivity, specificity and predictive values for the samples. 


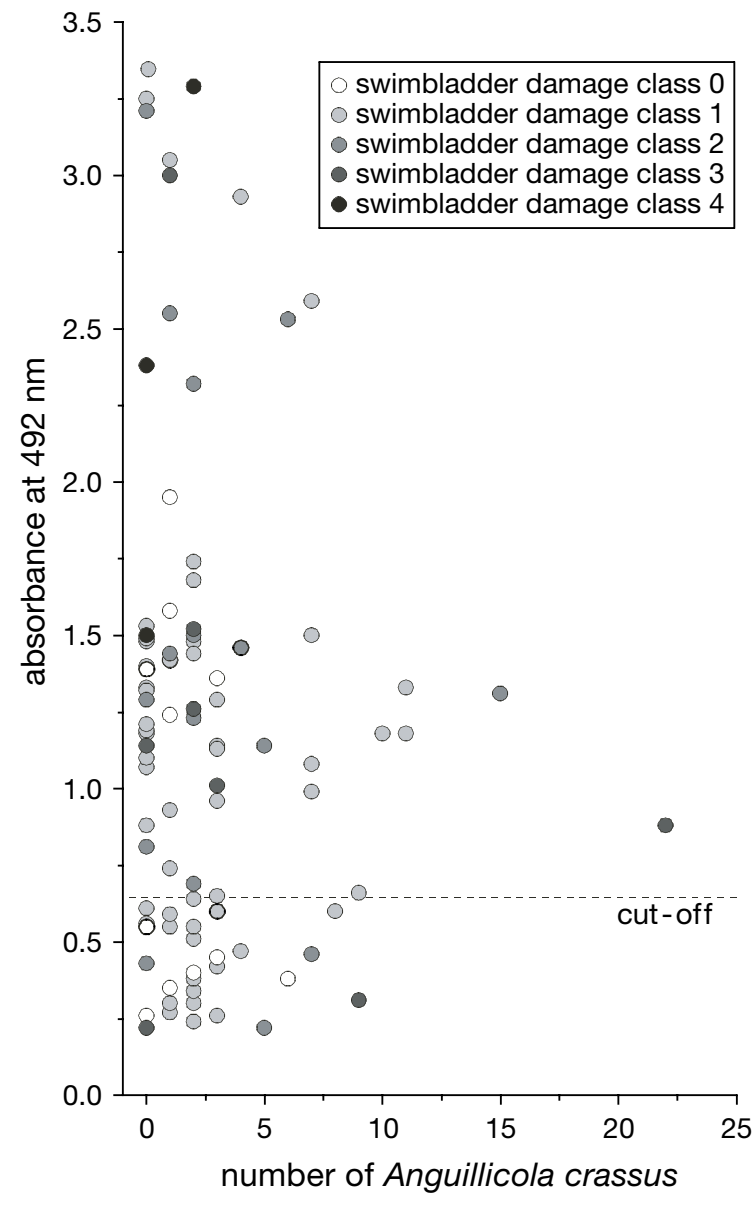

Fig. 2. ELISA results obtained from sera of the screening collective in relation to the total number of Anguillicola crassus found in the swimbladder and the detected swimbladder lesions

In contrast to the results obtained with sera from naturally infected eels, sera from the non-infected farm eels revealed a high specificity of $97.7 \%$. The intraand inter-assay coefficients of variation of the ELISA used in this study were $9.1 \%(\mathrm{n}=80)$ and $16.7 \%(n=12)$, respectively.

\section{SDS-PAGE and immunoblot}

SDS-PAGE revealed a satisfactory separation of proteins (Fig. 1). Each of the crude antigen preparations showed a characteristic complex pattern of protein bands. The pattern varied considerably between the different samples, depending on the prevailing proteins. The outer cuticle was characterised by 2 broad, blurry bands of about 105 and $96 \mathrm{kDa}$ and a gap in the protein pattern from 56 to $35 \mathrm{kDa}$.
The $\mathrm{L}_{3}$ was mainly distinguished from the adult nematode by 2 prominent bands at about $115 \mathrm{kDa}$.

Immunoblots performed with randomly selected ELISA-positive sera from 9 naturally infected eels and ELISA-negative sera from 6 uninfected farm eels are presented in Fig. 3. The most subtly diversified pattern of antigen bands was obtained with the body wall antigen preparation. All sera from naturally infected eels reacted to 3 proteins in the range of 120 to $135 \mathrm{kDa}$ as well as to 2 conspicuous broad bands of about 105 and $94 \mathrm{kDa}$. However, 5 control sera showed also a weak reaction to these proteins. Further proteins of a lower molecular weight, including strong bands of 71, 43, and $38 \mathrm{kDa}$ were only recognised by a part of the tested sera. As in all other antigen preparations, no reactions were observed in the control strip only incubated with the secondary and tertiary antibody (Fig. 3).

Immunoblots with the outer cuticle antigen preparation confirmed the strong reaction of positive sera to the 105 and $94 \mathrm{kDa}$ bands which were unified into 1 large band. However, most control sera showed a weak reaction to this band as well. Antigens of about $58 \mathrm{kDa}$ were not only recognised by naturally infected eels, but also by some control eels (Fig. 3).

Use of the antigen preparation from the anterior parts of adult Anguillicola crassus produced a result similar to that achieved with the body wall preparation, but in the high molecular weight range the pattern of bands was not as clear. Low molecular weight proteins in a range of 14 to $20 \mathrm{kDa}$ and 1 band of $28 \mathrm{kDa}$ were only observed in this fraction, but each was recognised only by a part of the naturally infected eels (Fig. 3). Not all the selected sera of naturally infected eels showed a significant positive reaction to antigens associated with the reproductive system, the intestinal wall and the intestinal content of adult A. crassus as well as to the somatic $\mathrm{L}_{3}$ antigen (Fig. 3). The crude antigen preparation from eel blood revealed only a very weak band at about $67 \mathrm{kDa}$ (Fig. 3).

Table 2. Sensitivity (Se), specificity $(\mathrm{Sp})$, positive predictive value $\left(\mathrm{PV}_{\mathrm{p}}\right)$ and negative predictive value $\left(\mathrm{PV}_{\mathrm{n}}\right)$ of the ELISA. The parameters were calculated for (1) actual infection with Anguillicola crassus, and/or swimbladder alterations; (2) actual infection with A. crassus; and (3) actual infection with adult $A$. crassus

\begin{tabular}{|c|c|c|c|c|c|c|}
\hline \multirow[t]{3}{*}{ ELISA } & \multicolumn{6}{|c|}{ Real condition } \\
\hline & \multirow{2}{*}{\multicolumn{2}{|c|}{$\begin{array}{c}\text { Infection and/or } \\
\text { swimbladder alteration } \\
\text { Positive Negative }\end{array}$}} & \multirow{2}{*}{\multicolumn{2}{|c|}{$\begin{array}{l}\text { Infection (larvae } \\
\text { and/or adults) } \\
\text { Positive Negative }\end{array}$}} & \multicolumn{2}{|c|}{$\begin{array}{c}\text { Infection } \\
\text { (adults) }\end{array}$} \\
\hline & & & & & Positive & Negative \\
\hline Positive & 67 & 1 & 55 & 13 & 46 & 22 \\
\hline \multirow[t]{2}{*}{ Negative } & 32 & 0 & 28 & 4 & 24 & 8 \\
\hline & \multicolumn{2}{|c|}{$\begin{aligned} \mathrm{Se} & =67.7 \% \\
\mathrm{Sp} & =0.0 \% \\
\mathrm{PV}_{\mathrm{p}} & =98.5 \% \\
\mathrm{PV}_{\mathrm{n}} & =0.0 \%\end{aligned}$} & \multicolumn{2}{|c|}{$\begin{aligned} \mathrm{Se} & =66.3 \% \\
\mathrm{Sp} & =23.5 \% \\
\mathrm{PV}_{\mathrm{p}} & =80.9 \% \\
\mathrm{PV}_{\mathrm{n}} & =12.5 \%\end{aligned}$} & \multicolumn{2}{|c|}{$\begin{aligned} \mathrm{Se} & =65.7 \% \\
\mathrm{Sp} & =26.7 \% \\
\mathrm{PV}_{\mathrm{p}} & =67.6 \% \\
\mathrm{PV}_{\mathrm{n}} & =25.0 \%\end{aligned}$} \\
\hline
\end{tabular}



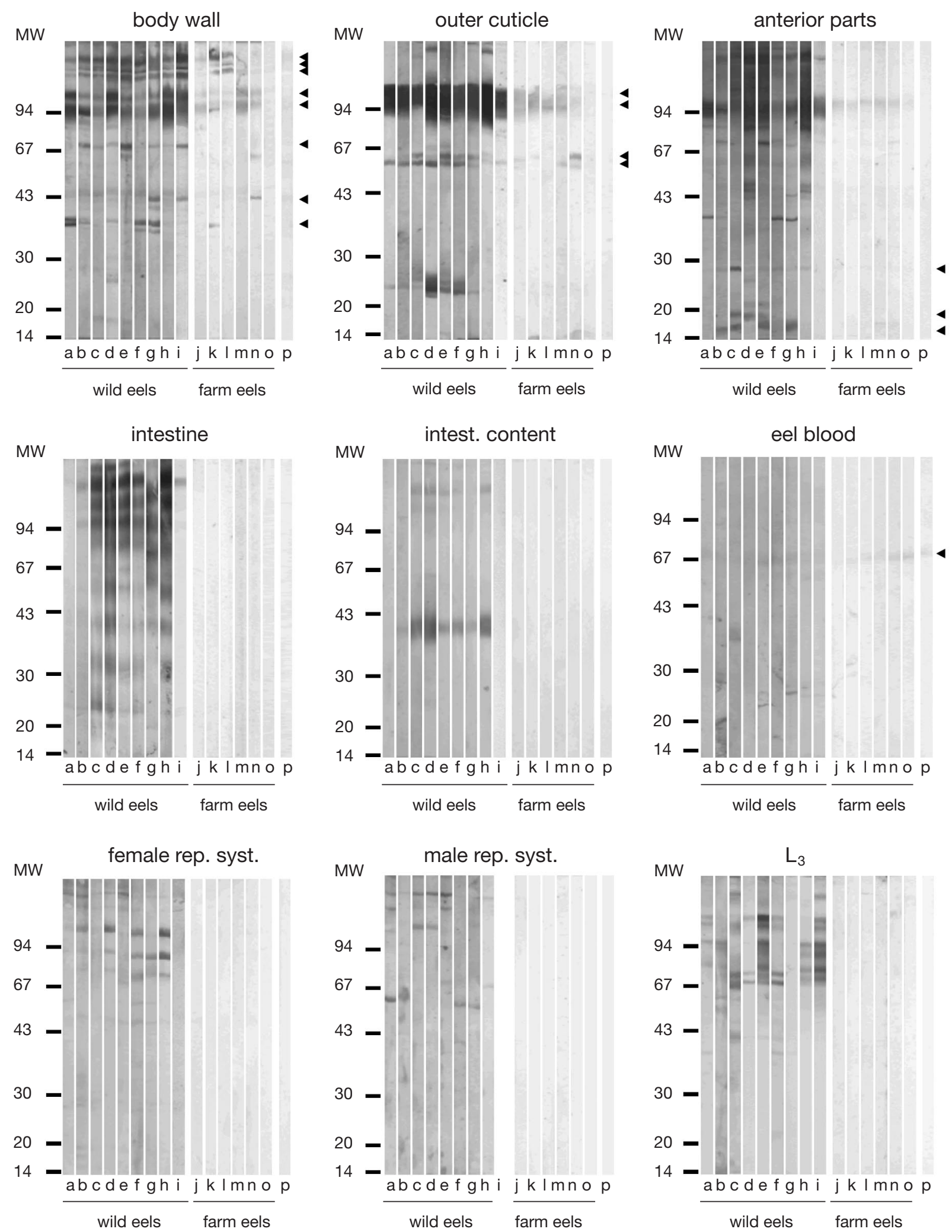

Fig. 3. Immunoblot analysis of Anguillicola crassus antigens with sera from 9 naturally infected, ELISA-positive wild eels (a-i) and 6 uninfected, ELISA-negative farm eels $(j-o)$. Lanes with common letters $(a-0)$ were stained with identical sera. Lane $p$ was only incubated with secondary and tertiary antibody. Molecular weights (MW) are indicated in kDa. rep.syst.: reproductive system. Bands mentioned in the text are indicated by arrowheads 


\section{Cross-reactivity}

The reactivity of antisera against Anguillicola crassus and Raphidascaris acus, tested with an ELISA using crude antigen preparations from the body wall of $A$. crassus and somatic $R$. acus, respectively, is presented in Fig. 4. When tested with body wall antigens of A. crassus, the homologous serum showed the strongest reaction. However, the antiserum against $R$. acus reacted clearly positive comparable to positive sera from naturally infected eels. When tested with somatic antigens of $R$. acus, the reactions of both homologous and heterologous sera were similar and only slightly stronger than the selected serum from a naturally infected eel. Sera from eels injected with PBS revealed low absorbance values.

SDS-PAGE analysis showed some correspondence between the protein pattern of Anguillicola crassus body wall and somatic Raphidascaris acus antigen preparations (Fig. 5A). Immunoblots using the crude body wall antigen from $A$. crassus revealed that the corresponding antiserum against $A$. crassus contained

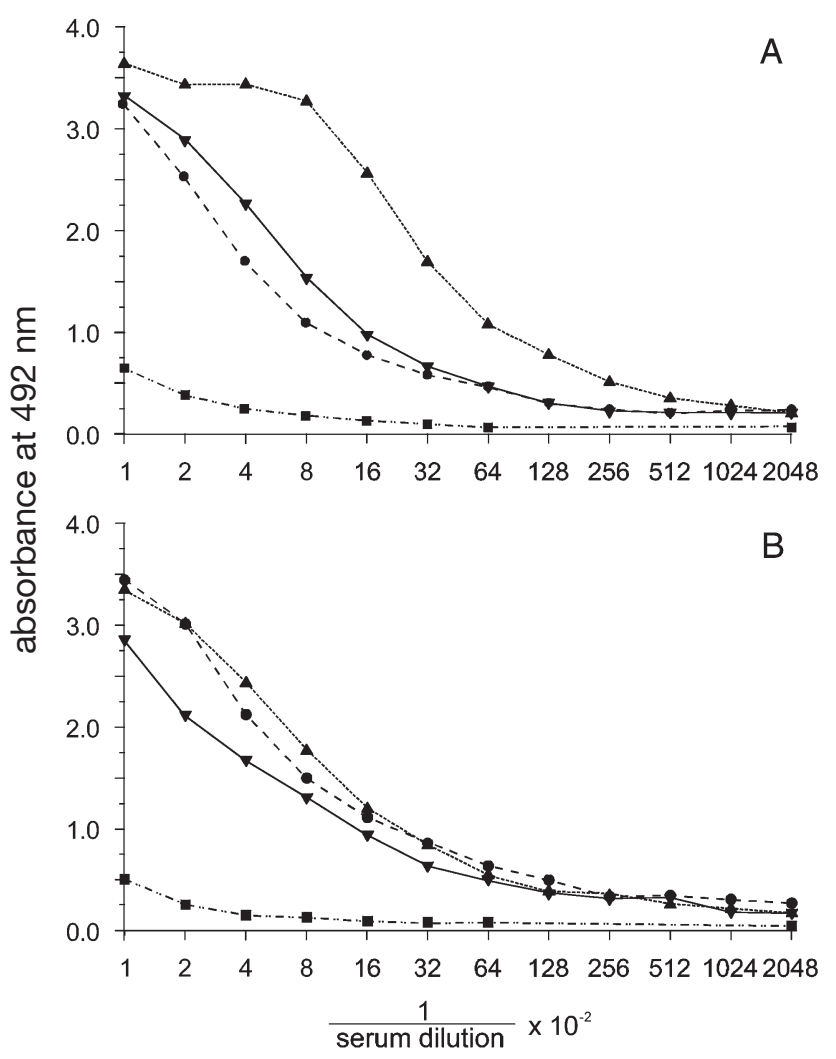

Fig. 4. ELISA results using plates coated with (A) Anguillicola crassus and (B) Raphidascaris acus crude antigen extracts. Plates were probed with $(\boldsymbol{\wedge})$ eel anti $A$. crassus serum, $(\bullet)$ eel anti $R$. acus serum, ( $\mathbf{v})$ serum from naturally infected eels and (匹) from sham immunised eels (each serum pooled from 3 samples)

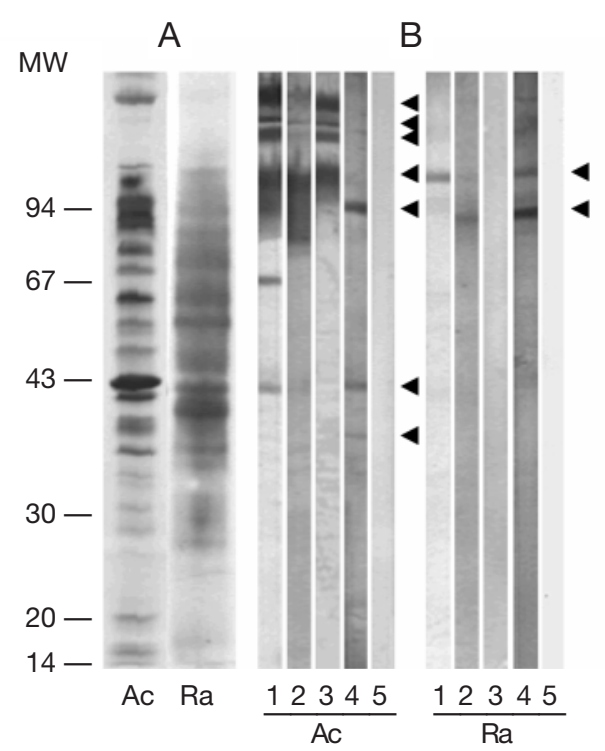

Fig. 5. (A) SDS-PAGE of body wall antigen preparations from adult Anguillicola crassus (Ac) and somatic Raphidascaris acus (Ra), silver stained. (B) Immunoblot analysis of body wall antigen preparation from adult Ac and of somatic Ra antigen preparation incubated with sera from feral eels $(1,2)$, antiserum against Ac (3), antiserum against Ra (4) and negative control serum (5). Molecular weights (MW) are indicated in $\mathrm{kDa}$. Bands mentioned in the text are indicated by arrowheads

antibodies to 3 antigens in the range of 120 to $135 \mathrm{kDa}$ and 1 of about $105 \mathrm{kDa}$. These bands were also detected by sera from eels naturally infected with $A$. crassus. The heterologous anti-Raphidascaris serum recognised 3 bands of approximately 95, 43 and $38 \mathrm{kDa}$ which were also detected by the feral eel sera (Fig. 5B). Antigens of $R$. acus were not detected by the heterologous anti-Anguillicola serum, but 2 bands of about 105 and $95 \mathrm{kDa}$ were recognised by the homologous antiserum. These bands were also detected by sera of feral eels. Control sera of eels injected with Freund's adjuvant and PBS did not show any reaction.

\section{DISCUSSION}

The validation of diagnostic assays requires a clear definition of an external criterion that describes the real condition of the individuals tested (Abel 1993). The 3 definitions for 'real positive' as determined by macro- and microscopic examination of the eels' swimbladders which were applied in the present study are justified below.

Firstly, the occurrence of larval and/or adult parasites must of course be determined as 'real positive'. Secondly, pathological alterations may indicate a previous infection with Anguillicola crassus (Molnár et al. 
1993, Haenen et al. 1996, Würtz \& Taraschewski 2000), and thus they can be regarded as positive in addition to an actual infection. This second definition assumes that a detectable level of specific antibodies may persist following recovery (Voller \& De Savigny 1981) and, therefore, tests for antibodies cannot discriminate between current and past infections. The third definition of a 'real positive' finding is reduced to an infection with adult $A$. crassus. Consequently, infections with only $\mathrm{L}_{3}$ are omitted. This takes into account that there is always a delay between infection and detectable specific antibody levels and, therefore, false negative results are typical for antibody detection systems (Voller \& De Savigny 1981).

The reproducibility (precision) of the described ELISA, expressed as the intra-assay coefficient of variation and the inter-assay coefficient of variation, was satisfactory. The most important parameter for an immunoassay, the predictive value (Voller \& De Savigny 1981), is related to specificity and sensitivity on the one hand, and to the prevalence of the disease on the other hand. Although the described ELISA reached a specificity of $97.7 \%$ for the uninfected farm eels, the results obtained for the test samples show that, in its present state, the ELISA is not applicable for detection of the rarely occurring negative eels within a highly infected population. The high positive predictive value should probably be attributed to the high prevalence of Anguillicola crassus rather than to the capacity of the test. Of course, a previous antigen contact of the non-infected eels is conceivable, even without a prevailing infection or any detectable swimbladder pathology. However, no external criterion exists to prove this assumption.

Our immunoblot analyses showed that the antigen preparations from the body wall and outer cuticle of adult worms contained high molecular weight antigens which were recognised by each of the 9 tested sera of naturally infected eels, indicating a potential suitability for diagnostic application. Antigens associated with the reproductive system, the intestinal wall and the intestinal content from adult Anguillicola crassus, as well as total $\mathrm{L}_{3}$, lack a diagnostic value because they were only partially detected by sera of naturally infected eels.

In contrast to the findings of Buchmann et al. (1991), not all tested sera of naturally infected eels recognised the $43 \mathrm{kDa}$ antigen of the body wall, which is probably identical to the $43 \mathrm{kDa}$ glutathione-s-transferase described by Nielsen \& Buchmann (1997). Furthermore, in the present study this band was also detected by negative control sera.

Using the antigen extract of the gelatinous outer cuticle of adult Anguillicola crassus, sera from naturally infected eels showed a strong reaction to antigens in the range of about $100 \mathrm{kDa}$. The silver stained gels and immunoblots with the crude antigen of the body wall indicated that at least 3 different antigens contribute to the large band obtained by immunoblotting. Although some negative control sera also showed a weak reaction with these antigens, the intensity of the reaction differed significantly between sera from infected and non-infected eels. Further purification and characterisation of the cuticular antigens might reveal more satisfying results.

The blurred character of the previously mentioned large band suggests that lipophilic antigens are involved (Westermeier 1990). Possibly these antigens are lipophilic glycoproteins, which are generally known to be important specific surface antigens of nematodes (Parkhouse et al. 1987). Because the adult Anguillicola crassus dwell in the swimbladder lumen, direct contact between the parasite and the host's immune system is limited to the period of blood sucking. Therefore, an immune response of the eel against cuticular antigens, which may be secreted by the adult worms and subsequently pass the swimbladder epithelium, seems plausible. Other studies revealed that the surface compartment of nematodes contains more specifically recognised antigens than the somatic compartment (Cabrera \& Parkhouse 1987). The characteristic broad band of about $100 \mathrm{kDa}$ seems to be stage specific since it was not found using the $\mathrm{L}_{3}$ antigen preparation.

Immunoblot analysis of normal eel blood incubated with positive eel sera revealed only a weak band of about $67 \mathrm{kDa}$, which probably represents the heavy chain of eel immunoglobulin (Van der Heijden et al. 1995, Hung et al. 1996). This band was not detectable in the antigen preparation of the parasite intestinal content, indicating that the eel immunoglobulin in the adult parasite gut was probably enzymatically decomposed.

Generally, a higher background was obtained with sera from feral eels compared to sera from farm eels, indicating a higher level of non-specific reactions. This is probably a result of the fact that feral eels are permanently exposed to a high variety of different pathogens in contrast to the farm eels, which were maintained in a protected environment. The difference in non-specific reactivity of sera from eels of different origin illustrates the importance of appropriate reference groups (Voller \& De Savigny 1981). However, if a serodiagnostic assay is used on feral eels, it is difficult or maybe even impossible to find a comparable Anguillicola crassus-free eel population.

Höglund \& Pilström (1995) and Nielsen \& Buchmann (1997) also tested the applicability of excretory/secretory (ES) antigens from adult Anguillicola crassus. Whereas the latter authors achieved good results, Höglund \& Pilström (1995) found high background values. This was probably due to a different method for the 
collection of ES antigens (Nielsen \& Buchmann 1997). If it can be confirmed that major secretions are located in the adult worm cuticle, as suggested in the present study, the mechanical isolation of the outer cuticle would provide a practical and reproducible method for their enrichment. In the present study, immunoblots with an antigen extract from the anterior parts of adult worms, including the oesophagus, were performed to detect antigens which might be secreted via the mouth during the ingestion of blood. Indeed, some low molecular weight antigens (14 to $28 \mathrm{kDa}$ ) were detected exclusively in this antigen preparation, but until now, it is uncertain whether these are secretions and correspond to the $90 \mathrm{kDa}$ aspartyl-proteinase which was identified by Polzer \& Taraschewski (1993). Because ES products have proved to be highly specific antigens in other serodiagnostic applications (Voller \& De Savigny 1981, Sundquist et al. 1988), further investigations have to examine this topic, especially with respect to cuticula-derived secretions and stagespecific proteolytic enzymes (Polzer \& Taraschewski 1993).

A well-known uncertainty in the serodiagnosis of helminthoses is constituted by cross-reactive antibodies. Especially antigens of nematodes often cause problems in the serodiagnosis (e.g. Voller \& De Savigny 1981, Parkhouse et al. 1987, De Leeuw \& Cornelissen 1991, Wakelin 1994). In this study it could be demonstrated that antibodies raised against Raphidascaris acus cross-react with at least 3 antigens from the body wall of Anguillicola crassus. As R. acus was also found at the sampling sites of the eels used in the present study (Sures et al. 1999b), the cross-reactivity of antibodies against $R$. acus with body-wall-associated antigens of $A$. crassus probably contributes to the false positive results yielded by ELISA.

The results presented in this study show that, in present state, neither ELISA nor immunoblotting are applicable for epizootiological purposes. This is not surprising, taking into account the persisting uncertainty in the serodiagnosis of human parasitoses (Kimmig et al. 1991, Janitschke et al. 1998). Since whole-worm antigen preparations caused problems, an improvement was made by the mechanical isolation of different fractions of adult Anguillicola crassus as suggested by Höglund \& Pilström (1995). However, these crude antigen preparations are still not clearly defined antigens and further biochemical purification and characterisation of antigens is recommended.

For epizootiological purposes simple dissection of eels provides a reliable, fast and low cost method to detect Anguillicola crassus infections. However, immunoserological tests are essential to investigate the immune response of eels against $A$. crassus. For experimental purposes, when a previous infection with
A. crassus as well as contact to other parasites can be excluded, the described serological methods are applicable. The ELISA based on body wall antigen preparation shows an acceptable precision and, when applied on sera from farm eels, it proved to be highly specific. Our results show that the outer cuticle of adult A. crassus contains highly immunogenic, probably secreted and stage-specific antigens.

Acknowledgements. We thank U. Weibel and J. Hirt for catching the feral eels and the 'Anglerverein Karlsruhe' for support in collecting copepods. Many thanks to D. Bachofer and B. Künzer for technical assistance.

\section{LITERATURE CITED}

Abel U (1993) Die Bewertung diagnostischer Tests. Hippokrates, Stuttgart

Békési L, Hornok S, Székely CS (1997) Attempts to analyse Anguillicola crassus and the humoral host response in eels (Anguilla anguilla) of Lake Balaton, Hungary. Act Vet Hung 45:439-445

Buchmann K, Pedersen LØ, Glamann J (1991) Humoral immune response of European eel Anguilla anguilla to a major antigen in Anguillicola crassus (Nematoda). Dis Aquat Org 12:55-57

Cabrera Z, Parkhouse RME (1987) Isolation of an antigenic fraction for diagnosis of Onchocerciasis. Parasite Immunol 9:39-48

De Leeuw WA, Cornelissen JBWJ (1991) Identification and isolation of a specific antigen with diagnostic potential from Dictyocaulus viviparus. Vet Parasitol 39:137-147

Egusa S (1979) Notes on the culture of the European eel (Anguilla anguilla L.) in Japanese eel-farming ponds. Rapp P-V Réun Cons Int Explor Mer 174:51-58

Haenen OLM, Van Wijngaarden TAM, Borgsteede FHM (1994) An improved method for the production of infective third-stage juveniles of Anguillicola crassus. Aquaculture 123:163-165

Haenen OLM, Van Wijngaarden TAM, Van der Heijden MHT, Höglund J, Cornelissen JBJW, Van Lengoed LAMG, Borgsteede FHM, Van Muiswinkel WB (1996) Effects of experimental infections with different doses of Anguillicola crassus (Nematoda, Dracunculoidea) on European eel (Anguilla anguilla). Aquaculture 141:41-57

Hartmann F (1994) Untersuchungen zur Biologie, Epidemiologie und Schadwirkung von Anguillicola crassus Kuwahara, Niimi \& Itagaki 1974 (Nematoda), einem blutsaugenden Parasiten in der Schwimmblase des Europäischen Aals (Anguilla anguilla L.). Shaker, Aachen

Höglund J, Pilström L (1994) Purification of adult Anguillicola crassus whole-worm extract antigens for detection of specific antibodies in serum from the European eel (Anguilla anguilla) by ELISA. Fish Shellfish Immunol 4:311-319

Höglund J, Pilström L (1995) Mechanical isolation and characterization of antigens from adult Anguillicola crassus. Fish Shellfish Immunol 5:51-60

Holzhauer M (1988) Biochemische Labormethoden. Springer, Berlin

Hung HW, Lo CF, Tseng CC, Kou GH (1996) Humoral immune response of Japanese eel, Anguilla japonica Temminck \& Schlegel, to Pleistophora anguillarum Hoshina, 1951 (Microspora). J Fish Dis 19:243-250 
Janitschke K, Kimmig P, Seitz HM, Frosch M, Groß U, Hlobil H, Reiter-Owona I (1998) MiQ: Qualitätsstandards in der mikrobiologisch-infektiologischen Diagnostik. 4. Parasitosen. Gustav Fischer Verlag, Stuttgart

Kimmig P, Naser K, Frank W (1991) Seroepidemiologische Untersuchungen zur Toxokariasis des Menschen. Zentbl Hyg Umweltmed 191:406-422

Knopf K, Würtz J, Sures B, Taraschewski H (1998) Impact of low water temperature on the development of Anguillicola crassus in the final host Anguilla anguilla. Dis Aquat Org 33:143-149

Kuwahara A, Niimi A, Itagaki H (1974) Studies on a nematode parasitic in the air bladder of the eel, I. Description of Anguillicola crassa n.sp. (Philometridae, Anguillicolidae). Jpn J Parasitol 23:275-279

Lowry OL, Rosebrough NJ, Farr AL, Randall RJ (1951) Protein measurment with the Folin phenol reagent. J Biol Chem 193:265-275

Maizels RM, Blaxter ML, Robertson BD, Selkirk ME (1991) Parasite antigens, parasitic genes: a laboratory manual for molecular parasitology. Cambridge University Press, Cambridge, p 103-104

Molnár K (1994) Formation of parasitic nodules in the swimbladder and intestinal walls of the eel Anguilla anguilla due to infections with larval stages of Anguillicola crassus. Dis Aquat Org 20:163-170

Molnár K, Baska F, Csaba Gy, Glávits R, Székely CS (1993) Pathological and histopathological studies of the swimbladder of eels Anguilla anguilla infected by Anguillicola crassus (Nematoda: Dracunculoidea). Dis Aquat Org 15: 41-50

Moravec F (1992) Spreading of the nematode Anguillicola crassus (Dracunculoidea) among eel populations in Europe. Folia Parasitol 39:247-248

Moravec F, Taraschewski H (1988) Revision of the genus Anguillicola Yamaguti, 1935 (Nematoda: Anguillicolidae) of the swimbladder of eels, including descriptions of two new species, A. novazelandiae sp. n. and A. papernai sp.n. Folia Parasitol 35:125-146

Nielsen ME, Buchmann K (1997) Glutathione-s-transferase is an important antigen in the eel nematode Anguillicola crassus. J Helminthol 71:319-324

Parkhouse RME, Almond MM, Carbrera Z, Harnett W (1987) Nematode antigens in protection, diagnosis and pathology. Vet Immunol Immunopathol 17:313-324

Polzer M, Taraschewski H (1993) Identification and character-

Editorial responsibility: Wolfgang Körting,

Hannover, Germany ization of the proteolytic enzymes in the developmental stages of the eel-pathogenic nematode Anguillicola crassus. Parasitol Res 79:24-27

Sundquist B, Zakrisson G, Bech-Nielsen S, Bianco AE (1988) Preparation and evaluation of the specificity of Parafilaria bovicola antigen for detection of specific antibodies by ELISA. Vet Parasitol 28:223-235

Sures B, Knopf K, Taraschewski H (1999a) Development of Anguillicola crassus (Dracunculoidea, Anguillicolidae) in experimentally infected Balearic congers (Ariosoma balearicum, Anguilloidea, Congridae). Dis Aquat Org 39: $75-78$

Sures B, Knopf K, Würtz J, Hirt J (1999b) Richness and diversity of parasite communities in European eels (Anguilla anguilla) of the river Rhine, Germany with special reference to helminth parasites. Parasitology 119:323-330

Taraschewski H, Renner C, Mehlhorn H (1988) Treatment of fish parasites. 3. Effect of levamisole $\mathrm{HCl}_{\text {, metrifonate, }}$ fenbendazole, mebendazole and ivermectin on Anguillicola crassus (nematodes) pathogenic in the air bladder of eels. Parasitol Res 74:281-289

Van Banning P, Haenen OLM (1990) Effects of the swimbladder nematode Anguillicola crassus in wild and farmed eel, Anguilla anguilla. In: Perkins FO, Cheng TC (eds) Pathology in marine science. Academic Press, New York, p 317-330

Van der Heijden MHT, Rooijakkers JBMA, Booms GHR, Rombout JHWM, Boon JH (1995) Production, characterization and applicability of monoclonal antibodies to European eel (Anguilla anguilla L., 1758) immunoglobulin. Vet Immunol Immunopathol 45:151-164

Voller A, De Savigny D (1981) Diagnostic serology of tropical parasitic diseases. J Immunol Methods 46:1-29

Wakelin D (1994) Immunoparasitology. In: Smyth JD (ed) Introduction to animal parasitology, 3rd edn. Cambridge University Press, Cambridge, p 460-490

Westermeier R (1990) Elektrophorese-Praktikum. VCH, Weinheim

Würtz J, Taraschewski H (2000) Histopathological changes in the swimbladder wall of the European eel Anguilla anguilla due to infections with Anguillicola crassus. Dis Aquat Org 39:121-134

Würtz J, Taraschewski H, Pelster B (1996) Changes in gas composition in the swimbladder of the European eel (Anguilla anguilla) infected with Anguillicola crassus (Nematoda). Parasitology 112:233-238

Submitted: June 11, 2000; Accepted: August 17, 2000

Proofs received from author(s): September 22, 2000 